\title{
A MATERIALIDADE DO DIREITO INDÍGENA NO BRASIL: REFLEXOS DO INTEGRACIONISMO E DO MULTICULTURALISMO NAS SOCIEDADES TRIBAIS ${ }^{1}$
}

THE MATERIALITY OF INDIGENOUS LAW IN BRAZIL: REFLECTIONS OF INTEGRATIONISM AND MULTICULTURALISM IN TRIBAL SOCIETIES

Afonso Hermogenes Cintra FREITAS ${ }^{2}$

Ana Tereza Jacintho TEIXEIRA ${ }^{3}$

ISSUE DOI: $10.21207 / 2675-0104.2019 .909$

\section{RESUMO}

Com o advento da globalização, o Direito, como um todo, viu-se necessitado e se adaptar a esse novo cenário. Entretanto, o caráter unificador do fenômeno trouxe influências - positivas e negativas - em

\footnotetext{
${ }^{1} \mathrm{O}$ presente artigo sintetiza a monografia de conclusão da pesquisa, realizada para o Programa Interno de Bolsas de Iniciação Científica (PIBIC 2018-2019) da Faculdade de Direito de Franca (FDF), Franca/SP.

${ }^{2}$ Discente da Faculdade de Direito de Franca (FDF), Franca/SP. Bolsista do Programa Interno de Bolsas de Iniciação Científica (PIBIC 2018-2019).

${ }^{3}$ Graduada em História pela Universidade Estadual Paulista Júlio de Mesquita Filho (1972), em Direito pela Faculdade de Direito de Franca (1975), em Estudos Sociais pelo Centro Universitário Barão de Mauá (1975), em Geografia pelo Centro Universitário Barão de Mauá (1979), em Pedagogia pela Universidade de Franca (1984), e Ciências Sociais pela Universidade de Franca (1982). Mestra em Direito Público pela Universidade de Franca (2001) e Doutora em Direito - Universidad Del Museo Social Argentino (2007). Atualmente é professora titular da Faculdade de Direito de Franca e professora titular do Centro Universitário Municipal de Franca, atuando, também, como Chefe de departamento do curso de Ciências Econômicas. Tem experiência na área de Direito, atuando principalmente nos seguintes temas: Brasil, direito, trabalho, responsanbilidade civil e assédio moral.
} 
cada organismo que compõe a sociedade. Por consequências históricas, os indígenas se encontram à margem da tutela jurisdicional, e a antinomia existente entre o Estatuto do Índio (1973) e a Constituição Federal (1988), atualmente, provoca danos irreparáveis às comunidades tribais. O presente trabalho se propõe a analisar os efeitos da legislação, positivada de forma exclusiva pela sociedade não-indígena, naquela outra. Como método, a monografia utiliza de aspectos históricos e antropológicos para auxiliar na compreensão da figura indígena (arquetípica e real) e se desenvolve até as implicações máximas do multiculturalismo na atualidade. Os resultados, de certa forma, se apresentaram como o esperado. A questão latente reside no pluriculturalismo, que apesar de majoritariamente prejudicial às sociedades não integradas no movimento da globalização, propicia novas formas de interação entre esses grupos. É preciso, portanto, que haja um desenvolvimento no âmbito legislativo, especialmente no que concerne à política multicultural, para que ocorra a horizontalidade de tratamento entre as sociedades indígena e não-indígena brasileiras.

Palavras-chave: Direito Indígena. Integracionismo. Multiculturalismo. Sociedades tribais. Globalização.

\begin{abstract}
With the advento of globalization, Law, as a whole, found itself in need to adapt to this new scenario. However, the phenomenon's unifying character brought influences - both positive and negative - to each organism that makes up society. Due to historical consequences, indigenous meet at the edge of judicial protection, and the antinomy existing between Indian Statute (1973) and the Federal Constitution (1988), today, arouse irreparable damage to tribal communities. The presente study intends to analyze the effects of legislation, exclusively written by non-indigenous society, in the other one. As a method, the monography uses the historical and anthropological aspects to help the understanding of the indigenous figure (archetypal and real) and develops to the maximum implications of multiculturalism nowadays. The results, in a way, turned out as expected. The latent issue lies in pluriculturalism, which although largely detrimental to non integrated societies in the globalization movement, provides new forms of interaction between these groups. Therefore, there needs to be a development in the legislative sphere, especially with regard to multicultural politics, for horizontal treatment to occur between indigenous and non-indigenous societies from Brazil.
\end{abstract}

Keywords: Indigenous Law. Integrationism. Multiculturalism. Tribal societies. Globalization.

INTRODUÇÃO

Uma vez titular de direito, o indígena está submetido a todo o ordenamento jurídico do território em que se encontra. Todos os seus hábitos, ritos e comportamentos devem estar em conformidade com as normas positivadas pelo Estado. Urge, portanto, a necessidade de se analisar os efeitos das leis sobre a vida dos índios.

A Lei No 6.001, promulgada a 19 de dezembro de 1973, foi por muito tempo a norma brasileira mais relevante no âmbito do direito indígena. Apesar de ter sido, à época, uma referência mundial, o Estatuto do Índio não foi capaz de integrar o indígena ao restante da sociedade.

Posteriormente, com o advento da Constituição em 1988, um novo problema surgiu: a Carta Maior já não tinha como fulcro a integração 
do índio à sociedade, como esperava a Lei de 1973, mas visava a um multiculturalismo nacional, em que os indígenas teriam liberdade para ingressar à sociedade nacional, conforme (quando e se) quisessem.

A antinomia gerada provocou danos irreparáveis às comunidades indígenas brasileiras, principalmente no que concerne à percepção do índio e seu lugar no mundo. Mesmo nos dias atuais, o indivíduo que nasce em uma sociedade tribal encontra dificuldades em se reconhecer e ser reconhecido.

Além de ser um tema pouco estudado no universo jurídico, o Direito Indígena anda ameaçado pelas políticas públicas recentes iniciadas nas últimas gestões presidenciais, marcadas pela constante alteração de presidentes da Funai (Fundação Nacional do Índio), mostrando nítida instabilidade governamental no assunto.

Neste cenário de insegurança jurídica, a pesquisa tem o papel fundamental de incitar uma discussão séria nos âmbitos acadêmico e social sobre esse grupo de indivíduos que, infelizmente, se vê desamparado pelo Estado.

\section{O INDÍGENA NO BRASIL}

Durante muitas décadas, foi predominante essa visão que classificava o índio como um ser primitivo. A justificativa moral para o colonialismo lusitano - assim como se deu com o imperialismo na África e na Ásia, no século XIX - residia não somente na missão de levar a civilização para os povos ameríndios, mas também a sua própria salvação.

É notório, entretanto, que a evangelização cristã foi uma mera tentativa de conferir um viés moral à escravidão. A bula papal Romanus Pontifex, datada a 8 de janeiro de 1454, consentia, explicitamente, que o rei Afonso $\mathrm{V}$ e o infante D. Henrique, além de todos os reis de Portugal e seus descendentes, subjugassem os habitantes do Novo Mundo:

Guinéus e negros tomados pela força, outros legitimamente adquiridos foram trazidos ao reino, o que esperamos progrida até a conversão do povo ou ao menos de muitos mais. Por isso nós, tudo pensando com devida ponderação, concedemos ao dito rei Afonso a plena e livre faculdade, entre outras, de invadir, conquistar, subjugar a quaisquer sarracenos e pagãos, inimigos de Cristo, suas terras e bens, a todos reduzir à servidão e tudo praticar em utilidade própria e dos seus descendentes. Tudo declaramos pertencer de 
direito in perpetuum aos mesmos d. Afonso e seus sucessores, e ao infante. $^{4}$

A célebre bula Inter Coetera, de 4 de maio de 1493, além de dividir os territórios do Novo Mundo (a serem descobertos) entre Portugal e Espanha, também revela o sentimento escravocrata sempre presente nos documentos oficiais da Igreja:

A Vós e a vossos herdeiros e sucessores (reis de Castela e Leão) pela autoridade do Deus onipotente a nós concedida em S. Pedro, assim como do vicariado de Jesus Cristo, a qual exercemos na terra, para sempre, no teor das presentes, vô-las doamos, concedemos e entregamos com todos os seus domínios, cidades, fortalezas, lugares, vilas, direitos, jurisdições e todas as pertenças. E a vós e aos sobreditos herdeiros e sucessores, vos fazemos, constituímos e deputamos por senhores das mesmas, com pleno, livre e onímodo poder, autoridade e jurisdição. [...] sujeitar a vós, por favor da Divina Clemência, as terras firmes e ilhas sobreditas, e os moradores e habitantes delas, e reduzi-los à Fé Católica. ${ }^{5}$

Infelizmente a evangelização caiu como um flagelo sobre os povos indígenas, criando cicatrizes que são visíveis até hoje. O resultado além do quase completo desaparecimento das crenças tribais - foi o surgimento de uma religiosidade nova, "abrasileirada". As mamelucas (mulheres de ascendência branca e indígena):

[...] já não sendo índias, procuravam espaço para ser alguma categoria de gente digna. A única que se lhes abria era de fiéis contritas dos santos católicos, seguidoras entusiastas dos cultos. Essa foi a única conversão que os padres alcançaram. Elas foram, de fato, as implantadoras do catolicismo popular santeiro no Brasil $[\ldots]^{6}$

Conclui-se, portanto, que o índio brasileiro teve um papel de destaque na formação religiosa do Brasil, ainda que suas crenças, em sua maioria, tenham caído no esquecimento.

Paralelamente, a integração do povo indígena à sociedade nacional não pode ser vista como um fator capaz de descaracterizálo. A exemplo disso, o povo português, nos dias de hoje, já não possui exatamente os mesmos costumes (língua, formas de

\footnotetext{
${ }^{4}$ RIBEIRO, Darcy. O povo brasileiro: a formação e o sentido do Brasil. 3 ed. São Paulo: Global, 2015 , p. 32.

${ }^{5}$ Ibid., p. 33.

${ }^{6}$ Ibid., p. 69.
} 
tratamento, indumentária etc.) do período colonial - e, apesar disso, ainda mantém sua identidade lusitana. Da mesma forma, nas palavras de Darcy:

Ainda que crescentemente mestiçados e aculturados, permanecem sempre 'indígenas' na qualidade de alternos dos 'brasileiros', porque se veem e se sofrem como índios e assim também são vistos e tratados pela gente com que estão em contato. ${ }^{7}$

Por isso, a FUNAI (Fundação Nacional do Índio) estabelece como critérios para a definição de "indígena": a auto-declaração e consciência da identidade indígena e o reconhecimento dessa identidade por parte do grupo de origem. ${ }^{8}$

Ambos os critérios foram baseados na Convenção 169 da OIT (Organização Internacional do Trabalho) sobre Povos Indígenas e Tribais - promulgada em sua totalidade pelo Decreto $\mathrm{N}^{\circ} 5.051 / 2004$ - e no Estatuto do Índio (Lei $\mathrm{N}^{\circ}$ 6.001/1973). Este último caracteriza o indígena como, in verbis, "todo indivíduo de origem e ascendência pré-colombiana que se identifica e é identificado como pertencente a um grupo étnico cujas características culturais o distinguem da sociedade nacional". ${ }^{9}$

Assim, o indígena brasileiro é aquele que se vê como tal e que é visto pelos seus pares como semelhante, por partilhar os sofrimentos e as alegrias de ser índio.

\section{PRIMEIRAS ATUAÇÕES DO ESTADO NA QUESTÃO INDÍGENA}

As mudanças legislativas que ocorreram nos primeiros séculos de República pouco afetaram os indígenas, pois esses povos - por motivos linguísticos e econômicos - se encontravam à periferia do recém descoberto Brasil. E nesse ínterim, o Estado jamais interviria de forma que prejudicasse os portugueses e seus descendentes.

\footnotetext{
${ }^{7}$ Ibid., p. 69.

8 FUNAI. Quais os critérios utilizados para a definição de indígena? Disponível em: $\langle$ http://www.funai.gov.br/index.php/todos-ouvidoria/23-perguntas-frequentes/97-pergunta-3>. Acesso em: 10 dez. 2018.

9 BRASIL. Lei $\mathbf{N}^{\mathbf{0}}$ 6.001, Estatuto do índio, Brasília, DF, 19 dez. 1973. Disponível em: <http://www.planalto.gov.br/ccivil_03/Leis/L6001.htm>. Acesso em: 10 dez. 2018.
} 
Por esse ângulo, Beatriz Perrone-Moisés explica a ineficácia normativa da época:

Tomada em conjunto, a legislação indigenista é tradicionalmente considerada como contraditória e oscilante por declarar a liberdade com restrições do cativeiro a alguns casos determinados, abolir totalmente tais casos legais de cativeiro (nas três grandes leis de liberdade absoluta: 1609, 1680 e 1755), e em seguida restaurá-los. ${ }^{10}$

É importante ressaltar, também, a diferença legal que havia entre o índio considerado "amigo" e aquele que eventualmente seria um empecilho à coroa. O Estado tratava os índios que se submetiam ao cativeiro - material e espiritual - de forma mais branda em comparação aos que se rebelavam contra as mais diversas formas de opressão colonial. Quanto a isso, esclarece Perrone-Moisés:

Havia, no Brasil colonial, índios aldeados e aliados dos portugueses, e índios inimigos espalhados pelos "sertões". A diferença irredutível entre "índios amigos" e "gentio bravo" corresponde um corte na legislação e política indigenistas que, encaradas sob esse prisma, já não aparecem como uma linha tortuosa crivada de contradições, e sim duas, com oscilações menos fundamentais. Nesse sentido, pode-se seguir uma linha de política indigenista que se aplica aos índios aldeados e aliados e uma outra, relativa aos inimigos, cujos princípios se mantêm ao longo da colonização. Nas grandes leis de liberdade, a distinção entre aliados e inimigos é anulada e as duas políticas se sobrepõem. ${ }^{11}$

Uma simples analogia aplicada à atualidade revela um preconceito pouquíssimo discutido: até hoje os índios são separados entre "bons" e "maus", entre aqueles que vivem longe dos grandes centros urbanos, em aldeias no interior da Amazônia, e aqueles que cobram "pedágio" e dirigem grandes camionetes. Nas palavras de Tédney Moreira da Silva:

Embora sujeito a variações, o índio arquetípico é considerado universal (reportando-se a inumeráveis indivíduos e coletividades) e atemporal (pois que persiste a visão da remanência destes indivíduos e sociedades: os índios de hoje vivem como os antepassados). Qualidades como bondade, ingenuidade, singeleza, economia solidária e integração à natureza, dentre outras, são positivações de um caráter genericamente atribuído a todos os

${ }^{10}$ CARNEIRO DA CUNHA, Manuela. História dos índios no Brasil. São Paulo: Companhia das Letras, 1992, p. 117.

${ }^{11}$ CARNEIRO DA CUNHA, Manuela. História dos índios no Brasil. São Paulo: Companhia das Letras, 1992, p. 117. 
indígenas, em todos os tempos, e disputam a primazia de definição de quem seja o índio com negatividades que, paralelamente, também têm força nos discursos sustentados: maldade, maledicência, primitivismo, economia subsistente (entendida como precária) e selvageria, vez ou outra, são proferidas para determinar a natureza do índio. Além do abundante ou aquém do ínfimo, o índio arquetípico é o ser da desmedida. ${ }^{12}$

\section{A CONCRETUDE DO DIREITO INDÍGENA BRASILEIRO}

É importante destacar algumas normas que influenciaram o cenário indigenista no século pós-independência. José Bonifácio, em seu projeto de lei apresentado à Assembleia Geral Constituinte (trabalho conhecido como Apontamentos para a civilização dos índios do Brasil), propõe a integração dos índios à sociedade nacional ${ }^{13}$, introduzindo, ainda que de forma embrionária, a lógica integracionista (assimilacionista), que legalmente só estaria presente no Estatuto do Índio, em 1973.

$\mathrm{O}$ conselheiro de D. Pedro I chegou a apresentar dois projetos de lei à elite agrária, majoritária, há muito, no Congresso. Em um deles, inclusive, Bonifácio incentivava a introdução gradual dos índios à sociedade - recomendando que, com cautela, todos os homens fossem pouco a pouco integrados à nação, sendo devidamente preparados para o trabalho produtivo.

A assimilação proposta pelo estadista compreendia nada mais que um estratagema de aculturação dos povos silvícolas brasileiros, que deveriam - segundo o projeto - adotar a língua e os costumes nacionais:

Os índios são um rico tesouro para o Brasil se tivermos juízo e manha para aproveita-los. Cumpre ganhar-lhes a vontade tratandoos com bom modo, e depois pouco a pouco inclinar sua vontade ao trabalho e instrução moral, fazendo-os ver que tal é o verdadeiro interesse, e que devem adotar os nossos costumes, e sociedade. Eles

\footnotetext{
${ }^{12}$ SILVA, Tédney Moreira da. No banco dos réus, um índio: criminalização de indígenas no Brasil. São Paulo: IBCCRIM, 2016, p. 29.

${ }^{13}$ COSTA, Maria Luisa Furlan. O Projeto de José Bonifácio para a Civilização dos Índios do Brasil na Perspectiva da História da Educação. Universidade Estadual de Maringá. Disponível em: <http://www.sbhe.org.br/novo/congressos/cbhe1/anais/112_maria_luisa.pdf >. Acesso em: 1 ago. 2019.
} 
aprenderão a nossa língua, e se mesclarão conosco por casamentos e comércio. ${ }^{14}$

É possível aplicar ao projeto uma análise weberiana, que diagnostica a obrigatoriedade (e superior moralidade) do trabalho como uma mera justificativa de perpetuação do capitalismo e de seus membros mais abastados. Ora, se a condição financeira dos indivíduos é a força motriz que conduz toda sua vida, direcionar os índios ao trabalho é obrigálos a integrar um sistema político-econômico que a priori nega toda sua cultura (ausente de propriedade, lucro etc). Para Weber, "aquele que não adaptar seu modo de vida às condições de sucesso capitalista deve sucumbir ou, pelo menos, não poderá elevar-se". ${ }^{15}$

O documento está repleto de um etnocentrismo ${ }^{16}$ europeu, tão imperialista quanto saudosista, que descreve os índios como bárbaros selvagens, de forma semelhante àquela utilizada pelos portugueses:

Tenho pois mostrado pela razão, e pela experiência, que apesar de serem os índios bravos uma raça de homens inconsiderada, preguiçosa, e em grande parte desagradecida e desumana para conosco, que reputam seus inimigos, são contudo capazes de civilização, logo que se adotam meios próprios, e que há constância e zelo verdadeiro na sua execução. ${ }^{17}$

De qualquer forma, a política integracionista de Bonifácio não chegou a ser aplicada, uma vez que o país vivia sob uma constante ameaça separatista surgida no Nordeste, em especial na província de Pernambuco: ocorrida em 1824, a chamada Confederação do Equador. ${ }^{18}$ A isso, somase o clima de insegurança criado a partir da abdicação do trono de D. Pedro I em favor de seu filho, 7 anos depois.

Descaracterizar o apego dos povos índios à terra por não haver incutida neles a ideia de propriedade é um equívoco comum, e que é há muito utilizado no discurso etnocêntrico (presente desde o período recente

\footnotetext{
${ }^{14}$ ANDRADA E SILVA, José Bonifácio de. Apontamentos para a civilização dos índios bravos do império do Brasil in DOLHNIKOKK, Mirian (org). Projetos para o Brasil/José Bonifácio de Andrada e Silva, p.144-145.

${ }^{15}$ WEBER, Max. A ética protestante e o espírito do capitalismo. São Paulo: Martin Claret, 2013, p. 73.

${ }^{16}$ Ter a própria cultura como referencial moral e valorativo ao analisar outras culturas (ROCHA, 1989, p. 5).

${ }^{17}$ ANDRADA E SILVA, José Bonifácio de. Apontamentos para a civilização dos índios bravos do império do Brasil in DOLHNIKOKK, Mirian (org). Projetos para o Brasil/José Bonifácio de Andrada e Silva, p. 101.

${ }^{18}$ PAIM, Antonio. A questão indígena. Brasília: Senado Federal, Conselho Editorial, 2017, p. 25.
} 
pós-independência até os dias atuais). Em 19 de julho de 1826, o senador baiano Gonçalves Martins chegou a proferir:

\begin{abstract}
Uma aldeia de duzentos a trezentos índios umas vezes se achava a vinte léguas acima e daí a poucos dias vinte léguas mais abaixo; chamar-se-ão estes homens errantes, proprietários de tais terrenos? Poderá dizer-se que eles têm adquirido direito de propriedade? Por que razão não se aldeiam fixamente como nós? (...) Eu quisera que se me mostrasse a verba testamentária, pela qual nosso pai Adão lhes deixou aqueles terrenos em exclusiva propriedade. ${ }^{19}$
\end{abstract}

A última frase transcrita do discurso prenuncia (na realidade apenas anuncia) o grande interesse do Estado brasileiro em toda a questão indígena: a terra. Para tanto, é necessário que haja uma emancipação dos índios do restante da sociedade nacional. Ao removê-los do rol de sujeitos de direitos, seu território se torna um espaço ilegítimo (do ponto de vista jurídico), pronto para ser tomado pelas forças estatais em prol do avanço civilizatório. Descaracterizar os indígenas "é um poderoso meio de eliminar os sujeitos de direitos territoriais" (CARNEIRO DA CUNHA, 1987, p. 15). A globalização possui um papel fundamental nesse processo. Qualquer que tenha sido sua origem (seja nas Grandes Navegações dos séculos XV e XVI ou na Guerra Fria e seus momentos subsequentes), o fato é que ela deu origem a diversas teorias que buscavam explicar a dominação europeia imperialista na África, Ásia e América, em ambos os períodos.

Por ser um reflexo do avanço da dominação capitalista-ocidental, ela cria um sistema mundial fatal, do qual não se pode escapar. A aculturação dos índios, portanto, é um reflexo da disseminação do capitalismo e de seus processos culturais. É possível, entretanto, que haja um enriquecimento dos sistemas locais a partir desta situação (SAHLINS, 2007, p. 443).

Sahlins conclui que a principal necessidade é a de dar atenção aos povos indígenas, questionando como eles próprios percebem e entendem a temática: processo conhecido como "indigenização da modernidade" (Ibid., 1997, p. 53).

Nas palavras de Spency Pimentel:

Termos como "cultura original" ou "tradicional" perdem o sentido nesses novos contextos. Não se trata de "perder a cultura" ou ser

19 BRASIL. Annaes do Parlamento Brasileiro, Tomo III. Rio de Janeiro, RJ, 1824, p. 229. Disponível em: 〈http://bd.camara.leg.br/bd/handle/bdcamara/28879>. Acesso em: 10 ago. 2019. 
"aculturado", trata-se de incorporar elementos que vêm de fora e somar ao que já se tinha, buscando determinados objetivos. ${ }^{20}$

Ainda que tenham surgidos diversos dispositivos legais distintos, a tônica que vigorava no século XX se manteve até 1973, ano em que o Estatuto do Índio fora promulgado. $\mathrm{O}$ artigo $4^{\circ}$ da lei mencionada faz a seguinte divisão:

Art. $4^{\circ}$. Os índios são considerados:

I - Isolados - Quando vivem em grupos desconhecidos ou de que se possuem poucos e vagos informes através de contatos eventuais com elementos da comunhão nacional;

II - Em vias de integração - Quando, em contato intermitente ou permanente com grupos estranhos, conservam menor ou maior parte das condições de sua vida nativa, mas aceitam algumas práticas e modos de existência comuns aos demais setores da comunhão nacional, da qual vão necessitando cada vez mais para o próprio sustento;

III - Integrados - Quando incorporados à comunhão nacional e reconhecidos no pleno exercício dos direitos civis, ainda que conservem usos, costumes e tradições característicos da sua cultura. ${ }^{21}$

Nota-se, por conseguinte, a evidente defasagem temporal do Estatuto. Utilizar a incorporação aos hábitos da "sociedade nacional" como critério determinante da capacidade é supervalorizar a cultura considerada civilizada (aquela de origem ibérica e ocidental), tornando a transição desses povos algo a ser buscado - reafirmando o aspecto integracionista da lei.

É importante mostrar que há uma diferença teórica relevante entre os termos integracionismo e assimilacionismo ${ }^{22}$. A integração se refere à relação interétnica entre sociedades indígenas e não indígenas em que a primeira não se dilui culturalmente na segunda. A assimilação, por sua vez, está ligada à perda total - ou mesmo a um mero prejuízo - da identidade étnica de uma cultura perante outra (SILVA, 2016. p. 41).

\footnotetext{
${ }^{20}$ PIMENTEL, Spency. O índio que mora na nossa cabeça: sobre as dificuldades para entender os povos indígenas. São Paulo: Prumo, 2012, p. 43.

${ }_{21}$ BRASIL. Lei $\mathbf{N}^{\mathbf{0}}$ 6.001, Estatuto do índio, Brasília, DF, 19 dez. 1973. Disponível em: <http://www.planalto.gov.br/ccivil_03/Leis/L6001.htm>. Acesso em: 10 dez. 2018.

${ }^{22}$ Neste trabalho os termos são utilizados como sinônimos, com finalidade exclusivamente didática.
} 
Ademais, o problema reside justamente nos aspectos limítrofes da adaptação. Devido ao vácuo doutrinário e jurisprudencial, a imputabilidade penal do indígena é aferida por critérios dos mais variados:

Interrogatório - Índio alfabetizado, eleitor, integrado à civilização e fluente no idioma nacional - Desnecessidade da presença de intérprete - Inteligência do art. 193 do CPP. A presença de intérprete no interrogatório é necessária somente nos casos em que o acusado não fale ou não compreenda a língua portuguesa, conforme dispõe o art. 193 do CPP, sendo, portanto, desnecessária sua presença se o réu for índio alfabetizado, eleitor, integrado à civilização e fluente no idioma nacional. ${ }^{23}$

\section{Do mesmo modo:}

Índio - Silvícola totalmente integrado à sociedade - Pretendida aplicação dos benefícios previstos no art. 56, caput, e par. ún., da Lei 6.001/1973 - Inadmissibilidade se a pena-base foi fixada no mínimo legal e o regime prisional somente poderá ser o integralmente fechado, por tratar-se de crime hediondo. Os benefícios previstos no art. 56, caput, e par. ún. da Lei 6.001/1973 são destinados ao índio em fase de aculturação, razão pela qual não podem ser aplicados ao silvícola totalmente integrado à sociedade, cuja pena-base foi fixada no mínimo legal e cujo regime prisional somente poderá ser o integralmente fechado, por tratar-se de condenação por crime hediondo. ${ }^{24}$

O Direito Indígena evoluiu em muitos aspectos desde o período colonial. Mesmo assim, ainda há muito a ser corrigido, o que pode ser evidenciado por propostas como o Projeto de Lei № 2.057/1991, de autoria do ex-Senador Aloizio Mercadante. O art. 152, por exemplo, mostra um pouco do cuidado presente na elaboração do dispositivo, dando esperança (apesar da mora) à questão:

Art. 152. Não há crime se o agente indígena pratica o fato sem consciência do caráter delituoso de sua conduta, em razão dos calores culturais do seu povo. ${ }^{25}$

\footnotetext{
${ }^{23}$ Ibid., p. 539.

${ }^{24}$ REVISTA DOS TRIBUNAIS, v. 787, ano 90. São Paulo: Revista dos Tribunais, 2001, p. 560.

25 BRASIL. Projeto de Lei $\mathbf{N}^{\mathbf{0}}$ 2.057. Brasília, DF, 23 out. 1991. Disponível em: <https://www.camara.leg.br/proposicoesWeb/fichadetramitacao?idProposicao=17569>. Acesso em 14 ago. 2019.
} 


\title{
5 O FUTURO DAS SOCIEDADES TRIBAIS
}

O conceito de "aculturação", apesar de limitado em alguns aspectos, é bem definido por Eduardo Galvão:

\begin{abstract}
Aculturação foi definida como o estudo dos fenômenos que resultam quando grupos de indivíduos possuindo culturas diferentes entram em contato direto e permanente e das consequentes mudanças nos padrões culturais dêsses grupos. Distinguiu-se aculturação de mudança cultural, de que é um aspecto, e de assimilação, que pode ser uma fase de aculturação, e ainda de difusão, que, embora concorrente ao processo de aculturação, necessariamente não exige o contacto entre povos. ${ }^{26}$
\end{abstract}

Considerando que a assimilação é uma fase, um processo da própria aculturação, então estudar esse último conceito se faz fundamental para o compreendimento da pesquisa.

Assim sendo, o termo "aculturação" - tal como "etnocentrismo" e "sincretismo"27 - surgiu no ramo da Antropologia, ainda que a História se beneficie interdisciplinarmente da utilização desses termos. No início, um dos principais difusores do termo foi o antropólogo Nathan Watchel (SILVA, 2006, p. 15).

O francês alega que o termo é muito útil no estudo cultural de uma sociedade, incluindo das mudanças decorrentes de influências externas - causadas pelo contato intercultural consequente da inclusão de elementos extrínsecos. Aculturação, segundo ele, é todo fenômeno de conexão social advinda do contato entre duas (ou mais) culturas (Ibid.).

Há outras teorias que aplicam um viés de dominação ao termo. $\mathrm{O}$ professor Alfredo Bosi afirmava que na aculturação colonial é habitual que o sujeito mais moderno regrida o próprio $\operatorname{ethos}^{28}$ a estágios arcanos, de tal forma que:

Se procurarmos extrair um significado comum e mais geral dos desencontros apontados, surpreenderemos a dialética de um complexo formado de tempos sociais distintos, cuja simultaneidade é estrutural, pois estrutural é a compresença de dominantes e

\footnotetext{
${ }^{26}$ GALVÃO, Eduardo. Estudos sobre a aculturação dos grupos indígenas do Brasil. Universidade de São Paulo. Disponível em: <http://www.revistas.usp.br/ra/article/view/110360/108927>. Acesso em: 22 ago. 2019.

${ }^{27}$ FERREIRA, Aurelio Buarque de Holanda. Novo Dicionário da Língua Portuguesa. Rio de Janeiro: Nova Fronteira, 1986, p. 1589.

${ }^{28}$ Apesar da diferenciação terminológica entre os termos êthos (de Homero, no século VII a.C.) e éthos (de Ésquilo, entre 525-456 a.C.), ambos remetem aos usos e costumes como relativos um modo de viver e sua junção genérica seria como uma sabedoria usual e corriqueira (SPINELLI, 2009, p. 9).
} 
dominados, e estrutural é a sua contradição. O olho do colonizador não perdoou, ou mal tolerou a constituição do diferente e a sua sobrevivência. ${ }^{29}$

Ademais, o autor faz uma observação relevante. Para ele, há um dualismo existencial nessa concepção presente na vida indígena: uma das consequências mais poderosas, relativas à aculturação, reside no vínculo feito pelos missionários coloniais entre o ethos da tribo e poderes externos e mais fortes que a vontade do índio (BOSI, 1992, p. 68).

$\mathrm{O}$ fenômeno da aculturação, portanto, ocorre desde o primeiro contato entre as civilizações indígena e portuguesa. Com o passar do tempo, sua influência na vida de ambos os grupos (ainda que tenha sido infinitamente mais prejudicial aos índios, uma vez que subjugados) foi significativa. Por isso, muitos trabalhos acadêmicos se dedicam de forma exclusiva à análise dessa influência nas sociedades tribais. ${ }^{30}$

Como uma onda, é impossível impedir que ocorra a aculturação. Tanto porque a supressão da diversidade é uma das características da própria globalização, inevitável em um mundo capitalista - auxiliado pela horizontalidade da Internet.

Sendo assim, cabe à sociedade nacional, como um todo, preservar e respeitar o multiculturalismo, com um olhar especial ao modus vivendi do polo hipossuficiente (política e juridicamente falando) da relação, qual seja: o índio.

O multiculturalismo, apesar dos conflitos morais que causa, deve ter como fim único o desenvolvimento da sociedade, como um todo, através do aprimoramento da justiça social:

O multiculturalismo democrático defende o diálogo dentro da multiculturalidade das sociedades plurais. Ele visa o desenvolvimento humano e a justiça social. A diversidade (UNESCO, 2002) é compositora de tais sociedades em uma dimensão complexa. Imbuídos dessas certificações é situado o eixo vertebrador do multiculturalismo: a diferença. Esta, por sua vez, alocada em um âmbito de tolerância. O reconhecimento da

\footnotetext{
${ }^{29}$ GALVÃO, Eduardo. Estudos sobre a aculturação dos grupos indígenas do Brasil. Universidade de São Paulo. Disponível em: <http://www.revistas.usp.br/ra/article/view/110360/108927>. Acesso em: 22 ago. 2019.

${ }^{30}$ MOURA, Patrícia Garcia de; BATISTA, Luciana Rodrigues Vieira; MOREIRA, Emília Addison Machado. População indígena: uma reflexão sobre a influência da civilização urbana no estado nutricional e na saúde bucal. Rev. Nutr. Disponível em: $<$ http://www.scielo.br/scielo.php?script=sci_arttext\&pid=S1415-52732010000300013〉. Acesso em 26 ago. 2019.
} 
diferença implica, portanto, em uma revisão do tratamento dispensado às identidades nas democracias tradicionais. ${ }^{31}$

Nesse sentido, aplica-se o princípio da igualdade na diferença. Este pode ser definido como o tratamento diferenciado dado àqueles cidadãos incapazes de disputar em iguais condições com outros pertencentes a classes sociais mais altas na sociedade civil (HAAS, 2012, p. 1501).

O jurista Nery Junior expressa o princípio constitucional da isonomia da seguinte forma: "dar tratamento isonômico às partes significa tratar igualmente os iguais e desigualmente os desiguais, na exata medida de suas desigualdades. ${ }^{32}$

Assim sendo, apesar dos fatores negativos do multiculturalismo, é possível que haja um desenvolvimento da sociedade, resultante de um tratamento mais cauteloso (sob mais ampla tutela) àqueles grupos colocados em subposição na pirâmide social - como os indígenas.

Como bem explica José Wilson Rodrigues de Melo, o Canadá cuja cultura é uma simbiose de costumes ingleses, franceses e nativos além de declarar-se formalmente uma nação multiculturalista, passou por reordenações jurídicas ${ }^{33}$ como aquela que decorreu do Canadian Multiculturalism Act (CANADA, 1988).

O fim esperado, portanto, do multiculturalismo é único: sua própria ratificação pelo Estado inevitavelmente determinará o respeito à Cultura e às variantes dela. Uma nação expressamente multicultural impõe ao povo uma conduta necessariamente respeitosa perante o fato do multiculturalismo.

Este, por sua vez, pode ser visto não somente como o fim (referência ao aspecto sociológico da multiculturalidade, resultante do processo de globalização, inevitável) mas o próprio meio (aqui, referência à adoção formal ${ }^{34}$ do multiculturalismo por uma nação, feita pelo já citado

\footnotetext{
${ }^{31}$ HAAS, Ingrid Freire. Multiculturalismo na atualidade: o direito à cultura e sua expressão nos direitos humanos. Revista Eletrônica do Curso de Direito - PUC Minas Serro, Belo Horizonte, n. 5, p. 1497, maio 2012. Disponível em: <http://periodicos.pucminas.br/index.php/DireitoSerro/article/view/1954>. Acesso em: 26 ago. 2019. ${ }^{32}$ NERY JUNIOR, Nelson. Princípios do processo civil à luz da Constituição Federal. São Paulo: Revista dos Tribunais, 1999, p. 52.

${ }^{33}$ MELO, José Wilson Rodrigues de. Multiculturalismo, diversidade e direitos humanos. Universidade Federal do Tocantins. Disponível em: <https://educere.bruc.com.br/arquivo/pdf2015/16058_10161.pdf〉. Acesso em: 04 ago. 2019.

${ }^{34}$ Dada através da publicação de Atos, por exemplo, como aqueles já aqui citados.
} 
Canadá e outros, tais como Austrália ${ }^{35}$ e Inglaterra ${ }^{36}$ ), e que determina, dentre outras decorrências, a promoção do respeito cultural e entendimento dos processos evolutivos do multiculturalismo, essencial em um mundo globalizado.

\section{CONSIDERAÇÕES FINAIS}

As sociedades indígenas, desde o primeiro contato com os lusitanos, têm sofrido influências diretas em seu modo de vida. Ainda que tenham decorrido alguns efeitos positivos, a grande maioria deles, decorrentes do contato intercultural, foi - e ainda é - muito prejudicial aos índios.

Com a análise feita no presente estudo, é possível observar que o Direito possui um papel fundamental no reparo a esse dano (que vai desde uma formulação errônea do arquétipo indígena até os casos de determinação do índio traçados através de parâmetros explicitamente subjetivos). No que se refere à determinação do indígena - como isolados, em vias de integração e integrados - proposta pelo Estatuto do Índio, evidencia-se um vácuo legislativo, acompanhado por um vazio doutrinário também. A apresentação desse conteúdo segue com a proposta única de um reordenamento jurídico.

$\mathrm{O}$ mesmo resultado decorre na questão do multiculturalismo. Somente com a explícita declaração de multiculturalidade feita pelo Estado - realizada não apenas formalmente, mas seguida de uma política estatal completa, como o fez o Canadá, por exemplo - será possível uma amenização dos efeitos negativos, e inevitáveis, da globalização, a todos os organismos que compõem a sociedade nacional.

\section{REFERÊNCIAS}

ANDRADA E SILVA, José Bonifácio de. Apontamentos para a civilização dos índios bravos do império do Brasil in DOLHNIKOKK, Mirian (org). Projetos para o Brasil/José Bonifácio de Andrada e Silva.

\footnotetext{
${ }^{35}$ Ibid.

${ }^{36}$ Cujo reflexo fica claro, inclusive, desde o Education Reform Act (REINO UNIDO, 1988).
} 
ANTUNES, Paulo. Direito ambiental. São Paulo: Atlas, 2009, 1112p.

BOLSANELLO, Maria Augusta. Darwinismo social, eugenia e racismo "científico": sua repercussão na sociedade e na educação brasileiras. Universidade Federal do Paraná. Disponível em:

<http://www.scielo.br/pdf/er/n12/n12a14.pdf>. Acesso em: 10 ago. 2019.

BRASIL. Annaes do Parlamento Brasileiro, Tomo III. Rio de Janeiro, RJ, 1824, p. 229. Disponível em: 〈http://bd.camara.leg.br/bd/handle/bdcamara/28879>. Acesso em: 10 ago. 2019.

BRASIL. Carta Régia de 05 de novembro de 1808. Rio de Janeiro, RJ, 05 nov. 1808. Disponível em: <https://www2.camara.leg.br/legin/fed/carreg_sn/anterioresa1824/cartaregia-40263-5-novembro1808-572442-publicacaooriginal-95554-pe.html>. Acesso em 13 ago. 2019.

BRASIL. Carta Régia de 27 de outubro de 1831. Rio de Janeiro, RJ, 27 out. 1831. Disponível em: <https://www2.camara.leg.br/legin/fed/lei_sn/1824-1899/lei-37625-27-outubro-1831-564675publicacaooriginal-88614-pl.html>. Acesso em: 10 ago. 2019.

BRASIL. Convenção no 169 da Organização Internacional do Trabalho - OIT sobre Povos Indígenas e Tribais. Genebra, 27 jun. 1989. Disponível em: <http://www.planalto.gov.br/ccivil_03/_ato20042006/2004/decreto/d5051.htm>. Acesso em 15 ago. 2019.

BRASIL. Declaração Universal dos Direitos dos Povos Indígenas. Disponível em: $<$ https://pib.socioambiental.org/files/file/PIB_institucional/DECLARACAO_DAS_NACOES_UNID AS_SOBRE_OS_DIREITOS_DOS_POVOS_INDiGENAS.pdf >. Acesso em 18 ago. 2019.

BRASIL. Decreto-lei No 2.848, Código Penal. Rio de Janeiro, RJ, 07 dez. 1940. Disponível em: <http://www.planalto.gov.br/ccivil_03/decreto-lei/del2848compilado.htm〉. Acesso em 13 ago. 2019.

BRASIL. Lei No 3.071. Rio de Janeiro, RJ, 01 jan. 1916. Disponível em:

<https://www.jusbrasil.com.br/topicos/11494962/artigo-6-da-lei-n-3071-de-01-de-janeiro-de-1916>. Acesso em 14 ago. 2019.

BRASIL. Lei No 6.001, Estatuto do índio, Brasília, DF, 19 dez. 1973. Disponível em: <http://www.planalto.gov.br/ccivil_03/Leis/L6001.htm>. Acesso em: 10 dez. 2018.

BRASIL. Projeto de Lei No 2.057. Brasília, DF, 23 out. 1991. Disponível em: $<$ https://www.camara.leg.br/proposicoesWeb/fichadetramitacao?idProposicao=17569>. Acesso em 14 ago. 2019.

CALORE, Antonello. "Guerra giusta" tra presente e passato. Disponível em: <http://www.dirittoestoria.it/tradizione2/Calore-Guerra-giusta.htm>. Acesso em: 24 fev. 2019.

CAMINHA, Pero Vaz de. Carta a El Rei D. Manuel. Disponível em: <http://objdigital.bn.br/Acervo_Digital/livros_eletronicos/carta.pdf〉. Acesso em: 11 out. 2018.

CANADA. Canadian Multiculturalism Act. Canada, 21 jul. 1988. Disponível em: <https://lawslois.justice.gc.ca/eng/acts/c-18.7/page-1.html>. Acesso em: 28 ago. 2019.

CARNEIRO DA CUNHA, Manuela. História dos índios no Brasil. São Paulo: Companhia das Letras, 1992. 
CARNEIRO DA CUNHA, Manuela. Os direitos do índio. São Paulo: Brasiliense, 1987, 230p.

COSTA, Maria Luisa Furlan. O Projeto de José Bonifácio para a Civilização dos Índios do Brasil na Perspectiva da História da Educação. Universidade Estadual de Maringá. Disponível em: <http://www.sbhe.org.br/novo/congressos/cbhe1/anais/112_maria_luisa.pdf>. Acesso em: 1 ago. 2019.

DE LA TORRE, Miguel. The Problem with the Melting Pot. Disponível em: $<$ https://ethicsdaily.com/the-problem-with-the-melting-pot-cms-13647/>. Acesso em: 06 ago. 2019.

FERREIRA, Aurelio Buarque de Holanda. Novo Dicionário da Língua Portuguesa. Rio de Janeiro: Nova Fronteira, 1986, p. 1589.

FOUCAULT, Michel. Vigiar e punir. Petrópolis: Vozes, 1987, 348p.

FUNAI. Quais os critérios utilizados para a definição de indígena? Disponível em: <http://www.funai.gov.br/index.php/todos-ouvidoria/23-perguntas-frequentes/97-pergunta-3>. Acesso em: $10 \mathrm{dez} .2018$.

GALVÃO, Eduardo. Estudos sobre a aculturação dos grupos indígenas do Brasil. Universidade de São Paulo. Disponível em: <http://www.revistas.usp.br/ra/article/view/110360/108927>. Acesso em: 22 ago. 2019.

HAAS, Ingrid Freire. Multiculturalismo na atualidade: o direito à cultura e sua expressão nos direitos humanos. Revista Eletrônica do Curso de Direito - PUC Minas Serro, Belo Horizonte, n. 5, 2012. Disponível em: <http://periodicos.pucminas.br/index.php/DireitoSerro/article/view/1954〉. Acesso em: 26 ago. 2019.

IBGE. Política indigenista: do século VI ao século XX. Disponível em: $<$ https://brasil500anos.ibge.gov.br/territorio-brasileiro-e-povoamento/historia-indigena/politicaindigenista-do-seculo-xvi-ao-seculo-xx.html>. Acesso em: 24 fev. 2019.

LÉRY, Jean de. Viagem à terra do Brasil. Rio de Janeiro: Biblioteca do Exército Editora, 1961, 220p.

MALHEIRO, Agostinho Marques Perdigão. A escravidão no Brasil: ensaio historico-juridico-social. Rio de Janeiro: Typographia Nacional, 1867, 172p.

MOURA, Patrícia Garcia de; BATISTA, Luciana Rodrigues Vieira; MOREIRA, Emília Addison Machado. População indígena: uma reflexão sobre a influência da civilização urbana no estado nutricional e na saúde bucal. Rev. Nutr. Disponível em:

$<$ http://www.scielo.br/scielo.php?script=sci_arttext\&pid=S1415-52732010000300013 $>$. Acesso em 26 ago. 2019.

MPF. Protocolo de Consulta Prévia dos Povos Indígenas, Protocolo TIX Disponível em: $<$ http://www.mpf.mp.br/atuacao-tematica/ccr6/documentos-e-publicacoes/protocolos-de-consultados-povos-indigenas/docs/2016protocolotixxingu.pdf>. Acesso em: 18 ago. 2019.

NERY JUNIOR, Nelson. Princípios do processo civil à luz da Constituição Federal. São Paulo: Revista dos Tribunais, 1999, 245p. 
OLMO, Rosa del. A América Latina e sua criminologia. Rio de Janeiro: Revan, 2004, 328p.

PAIM, Antonio. A questão indígena. Brasília: Senado Federal, Conselho Editorial, 2017, 198p.

PIMENTEL, Spency. O índio que mora na nossa cabeça: sobre as dificuldades para entender os povos indígenas. São Paulo: Prumo, 2012, 88p.

POVOS INDÍGENAS NO BRASIL. Declaração da ONU sobre direitos dos povos indígenas. Disponível em: <https://pib.socioambiental.org/pt/Declara\%C3\%A7\%C3\%A3o_da_ONU_sobre_direitos_dos_povos _ind\%C3\%ADgenas>. Acesso em: 20 ago. 2019.

REINO UNIDO. Education Reform Act. Reino Unido, 29 jul. 1988. Disponível em: <http://www.legislation.gov.uk/ukpga/1988/40/contents>. Acesso em 04 ago. 2019.

REVISTA DOS TRIBUNAIS, v. 694, ano 82. São Paulo: Revista dos Tribunais, 1993.

REVISTA DOS TRIBUNAIS, v. 775, ano 89. São Paulo: Revista dos Tribunais, 2000.

REVISTA DOS TRIBUNAIS, v. 787, ano 90. São Paulo: Revista dos Tribunais, 2001.

RIBEIRO, Darcy. O povo brasileiro: a formação e o sentido do Brasil. $3^{\text {a }}$ edição. São Paulo: Global Editora, 2015. 358p.

ROCHA, Everardo P. Guimarães. O que é etnocentrismo. São Paulo: Brasiliense, 1989, 38p.

SILVA, José Justino de Andrade. "Collecção Chronologica da Legislação Portugueza - 1603-1612". Lisboa: Imprensa de J. J. A. Silva, 1854.

SILVA, Tédney Moreira da. No banco dos réus, um índio: criminalização de indígenas no Brasil. São Paulo: IBCCRIM, 2016, 310p.

SOUSA, Rainer. Escravidão indígena. Disponível em:

<https://brasilescola.uol.com.br/historiab/escravidao-indigena.htm〉. Acesso em: 24 fev. 2019.

SPINELI, Miguel. Sobre as diferenças entre éthos com épsilon e êthos com eta. Marília: Trans/Form/Ação, 2009. Disponível em: $<$ http://www.scielo.br/scielo.php?script=sci_arttext\&pid=S0101-31732009000200001 >. Acesso em: 22 ago. 2019.

SZTUTMAN, Renato. Ética e proféticas nas Mitológicas Levi-Strauss Universidade de São Paulo. Disponível em: <http://www.scielo.br/scielo.php?script=sci_arttext\&pid=S0104-

71832009000100012>. Acesso em: 11 ago. 2019.

WEBER, Max. A ética protestante e o espírito do capitalismo. São Paulo: Martin Claret, 2013, 300p. 